Acta Crystallographica Section B

Structural

Science

ISSN 0108-7681

Editor: Carolyn P. Brock

\title{
Crystal structure of $\mathrm{KLiSO}_{4}$ as a function of temperature
}

\author{
H. Schulz, U. Zucker and R. Frech
}

This electronic document was scanned from an archival copy of material deposited to accompany a paper published in an IUCr journal. In many cases the only accessible copy was a microfilm of a poor-quality original. 
domaln size [cm] mosaic spread ["] scale factor K$$
x
$$$$
y
$$$$
z
$$

$B(22)$

$B(33)$

$B(12)$

$B(13)$

$B(23)$

s

$O(1)$

$x$

$y$

$z$

$B(11)$

$B(22)$

$\mathrm{B}(33)$

$B(12)$

$B(13)$

$B(23)$
$193 \mathrm{~K}$

$398 \mathrm{~K}$

$0.010(1) 10^{-2}$

$23.3(8)$

$85.7 \quad(4)$

$1.3(1)$

$6149 .(3)$

0

0

10

Q. $0226(1)$

$B(11)$

$0.00587(4)$

$\mathrm{B}(11) / 2$

0

0

\section{$1 / 3$}

, 2/3

$0.20626(8)$

$0.20683(9)$

$0.20813(15)$

$0.0160(1)$

$0.00452(3)$

$0.00541(7)$
23.6 (2)

\section{$568 \mathrm{~K}$}

53.4 (2)
$0.0408(3)$

$0.00979(10)$
$0.0125(1)$

B $B(11)$

Q. $00365(3)$

$B(11) / 2$

. 0

$\therefore 0$

$\therefore 1 / 3$

$2 / 3$

$0.0367(7)$

$0.0610(8)$

$B(11)$

$0.0038(1)$

$B(11) / 2$

0

o
$0.0398(9)$

$0.0760(9$.

$0.0047(1)$
$0.0060(4)$

$0.0462(7)$

$0.1012(24)$ 


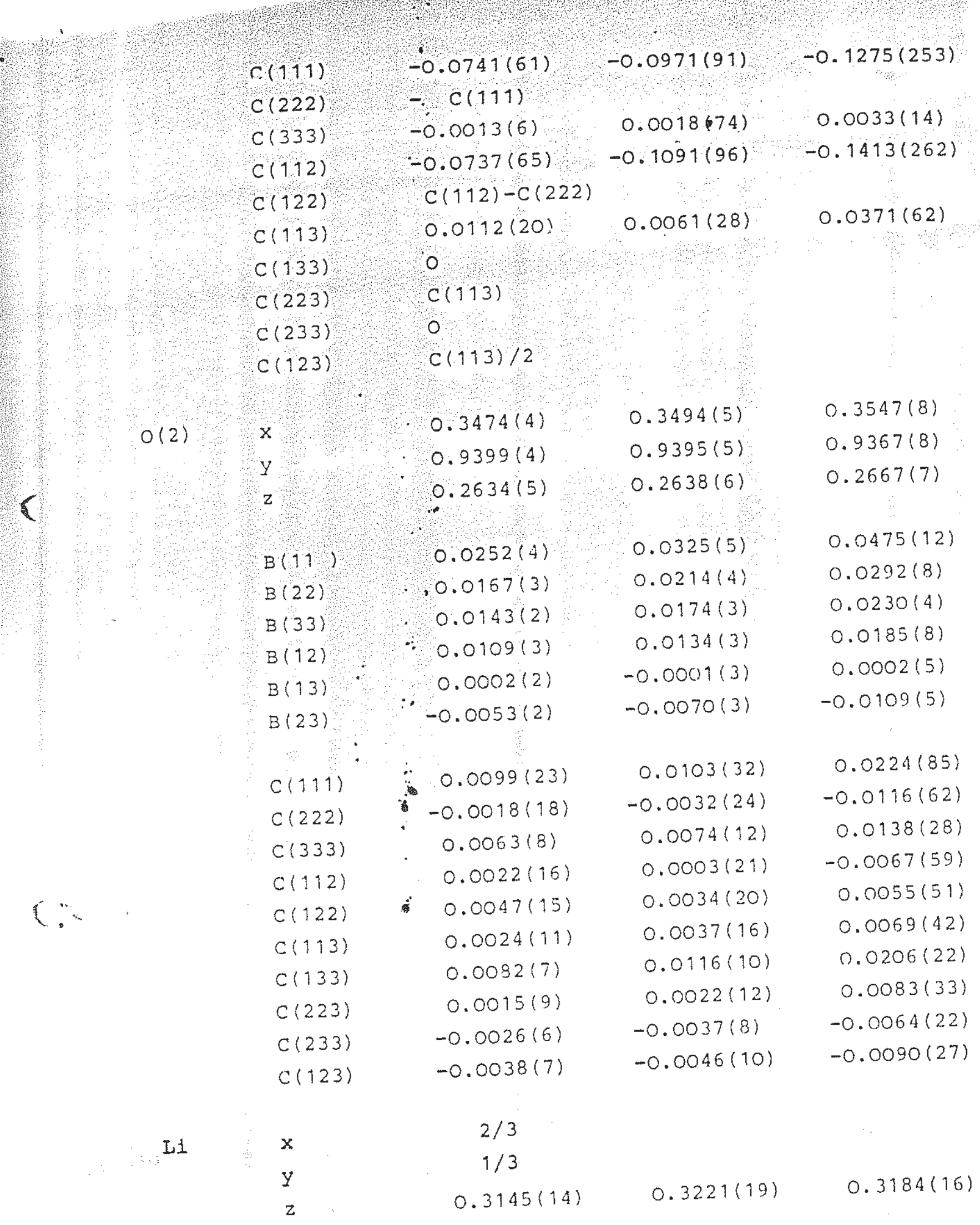




$$
\begin{aligned}
& \mathrm{B}(11) \text { ४ } 0.0168(9), 0.0224(10), 0.0344(22) \\
& \mathrm{B}(22) \cup \mathrm{B}(11) \\
& \mathrm{B}(33) \cup 0.0055(4) \quad 0.0082(8) \quad 0.0074(8) \\
& B(12)=B(11) / 2 \\
& \mathrm{~B}(13) \text { ? } \mathrm{O} \\
& B(23) \quad 0 \\
& c(111),-0.0042(38) \quad-0.0015(51) \quad 0.0282(157) \\
& C(222)-C(111) \\
& C(333), \quad-0.0014(15) \quad 0.0080(31) \quad 0.0016(37) \\
& \begin{array}{llll}
c(112) & -0.0034(40) & 0.0006(55) & 0.0487(172)
\end{array} \\
& C(122), \quad c(112)-C(222) \\
& \begin{array}{llll}
c(113) & -0.0020(20) & 0.0047(27) & -0.0062(54) \\
c(133) & \cdots & &
\end{array} \\
& C(223) \quad c(113) \\
& c(233) \quad 0 \\
& c(123): C(113) / 2
\end{aligned}
$$

The c-values are multiplied by $10^{3}$

Tho temperature factior has been used in the form:

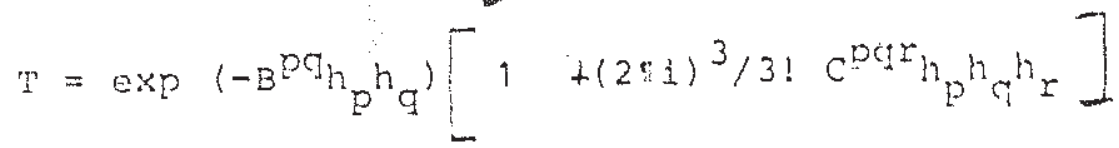

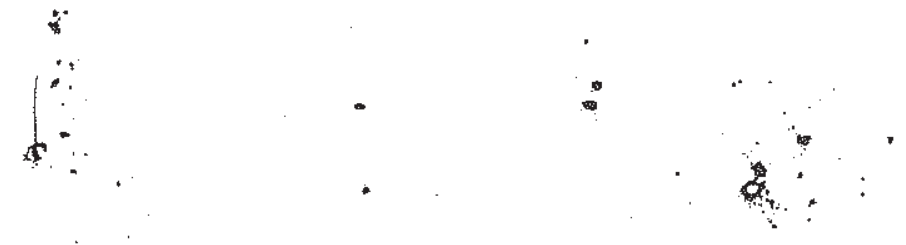




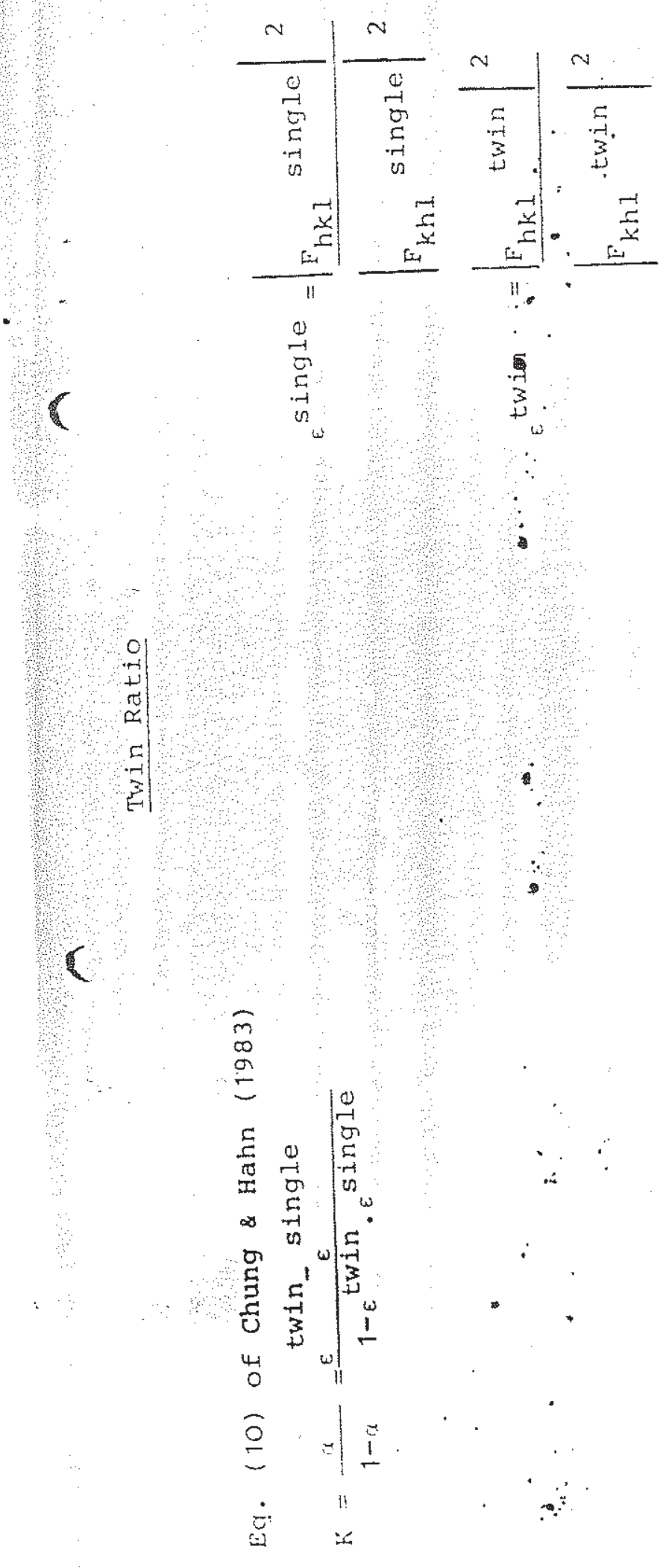

$$
\begin{aligned}
& \text { 丞 }
\end{aligned}
$$

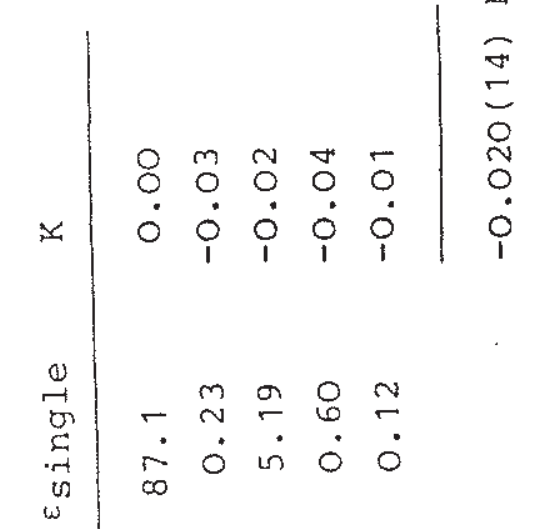

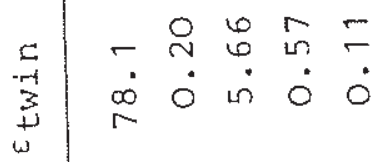

$$
\begin{aligned}
& \stackrel{5}{-1} \\
& \stackrel{0}{0} \rightarrow \sigma m \\
& \dot{\dot{m}} \dot{\sim} \underset{\sim}{\sim}
\end{aligned}
$$

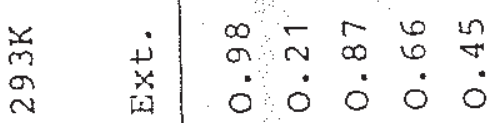

$$
\begin{aligned}
& \text { I3 } \\
& \text { E }
\end{aligned}
$$

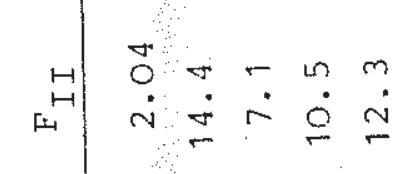

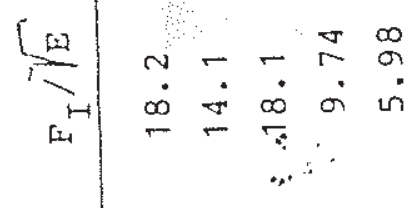

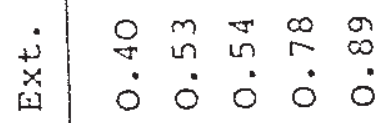

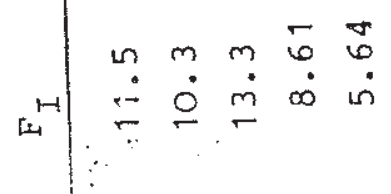

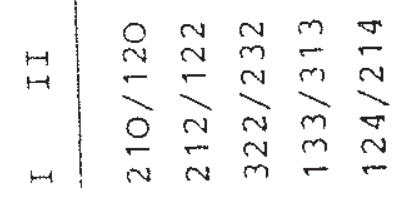




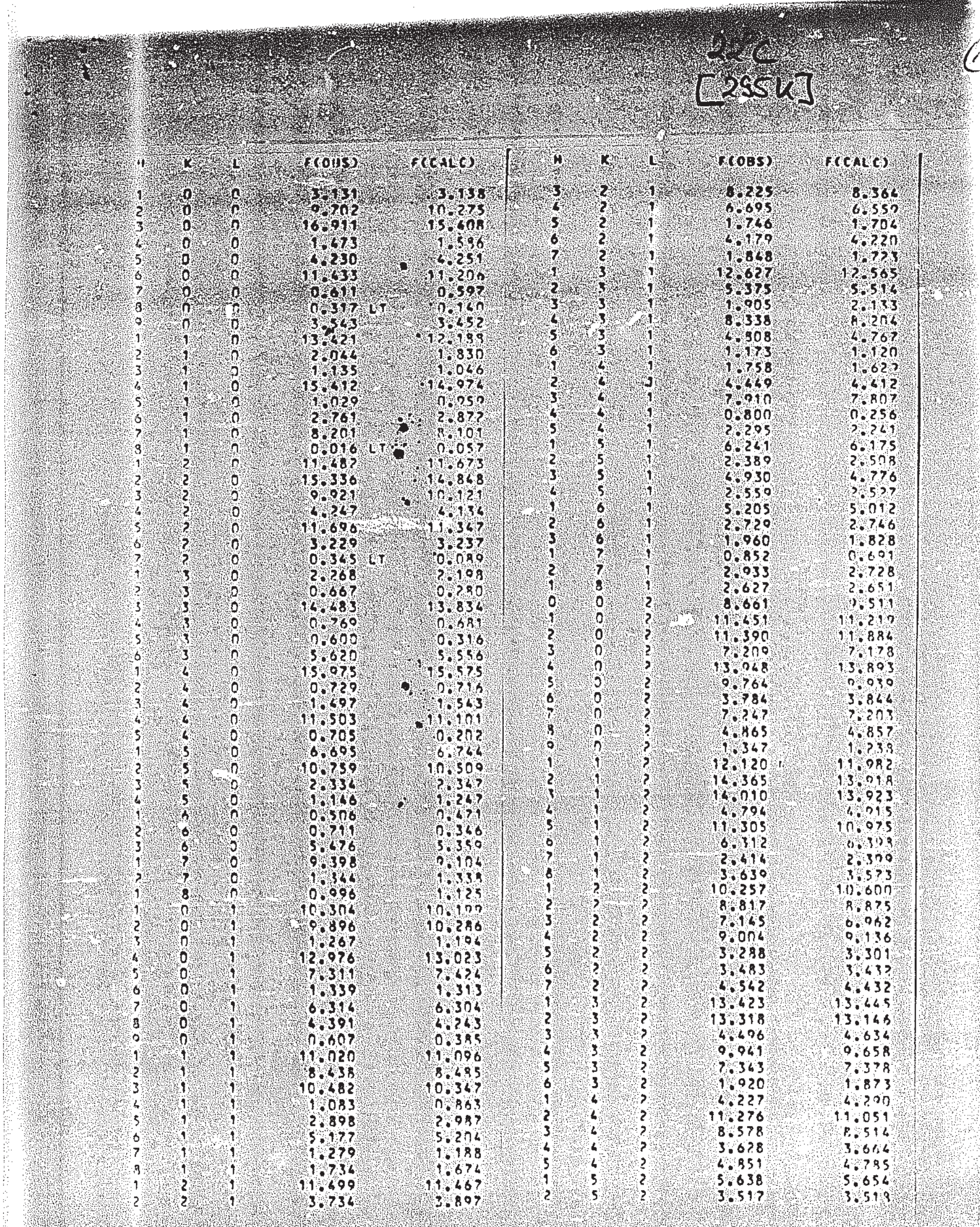









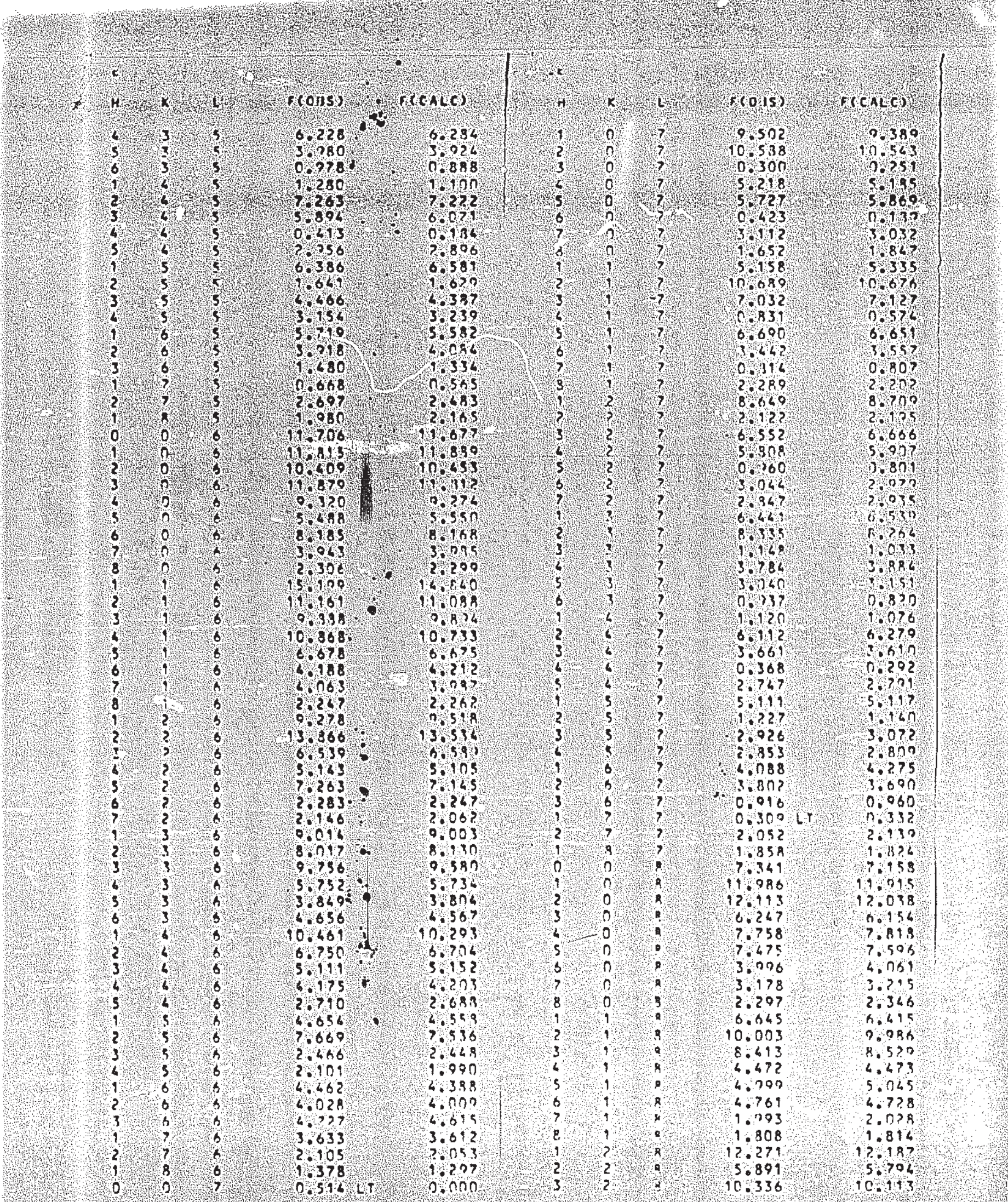




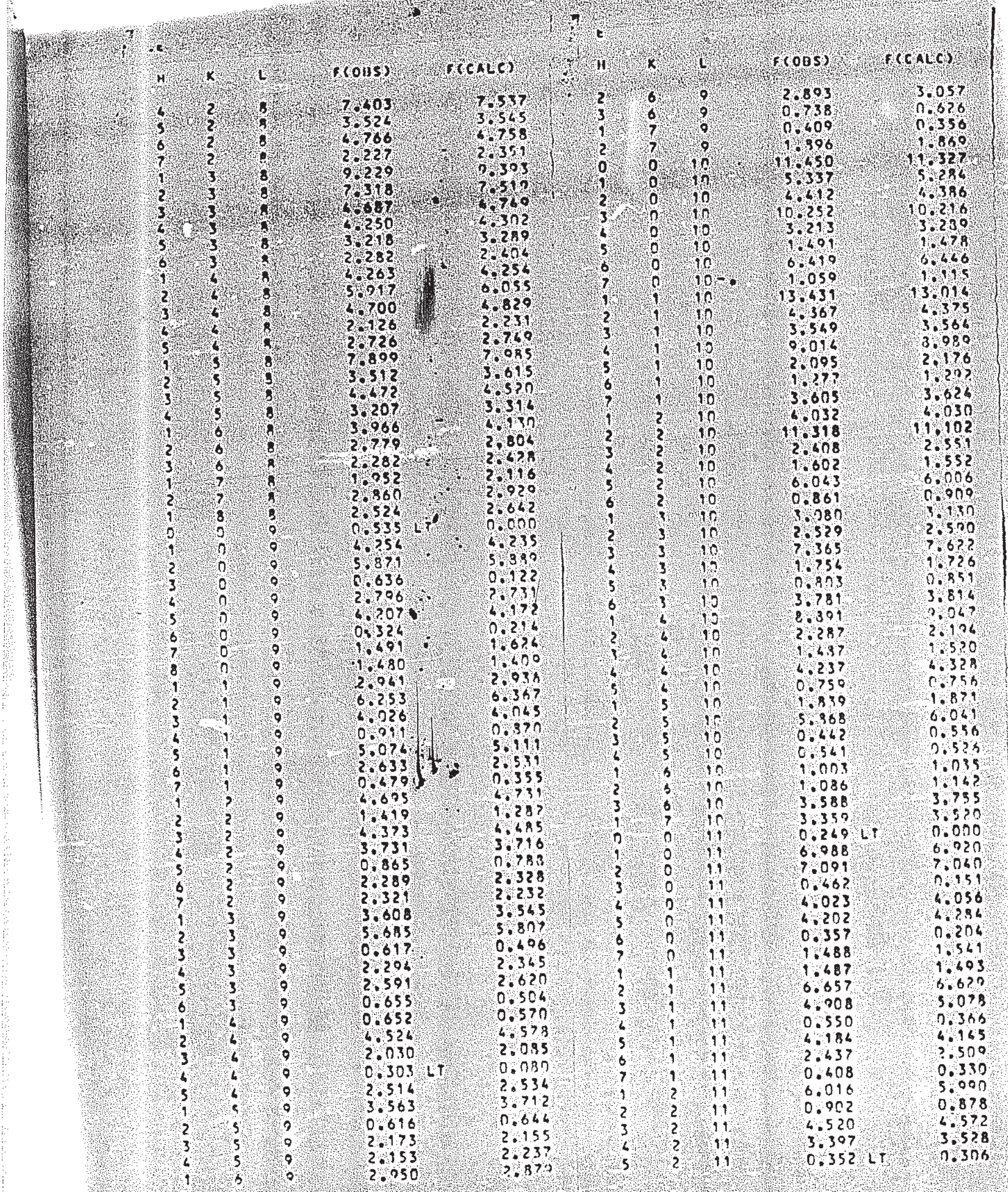




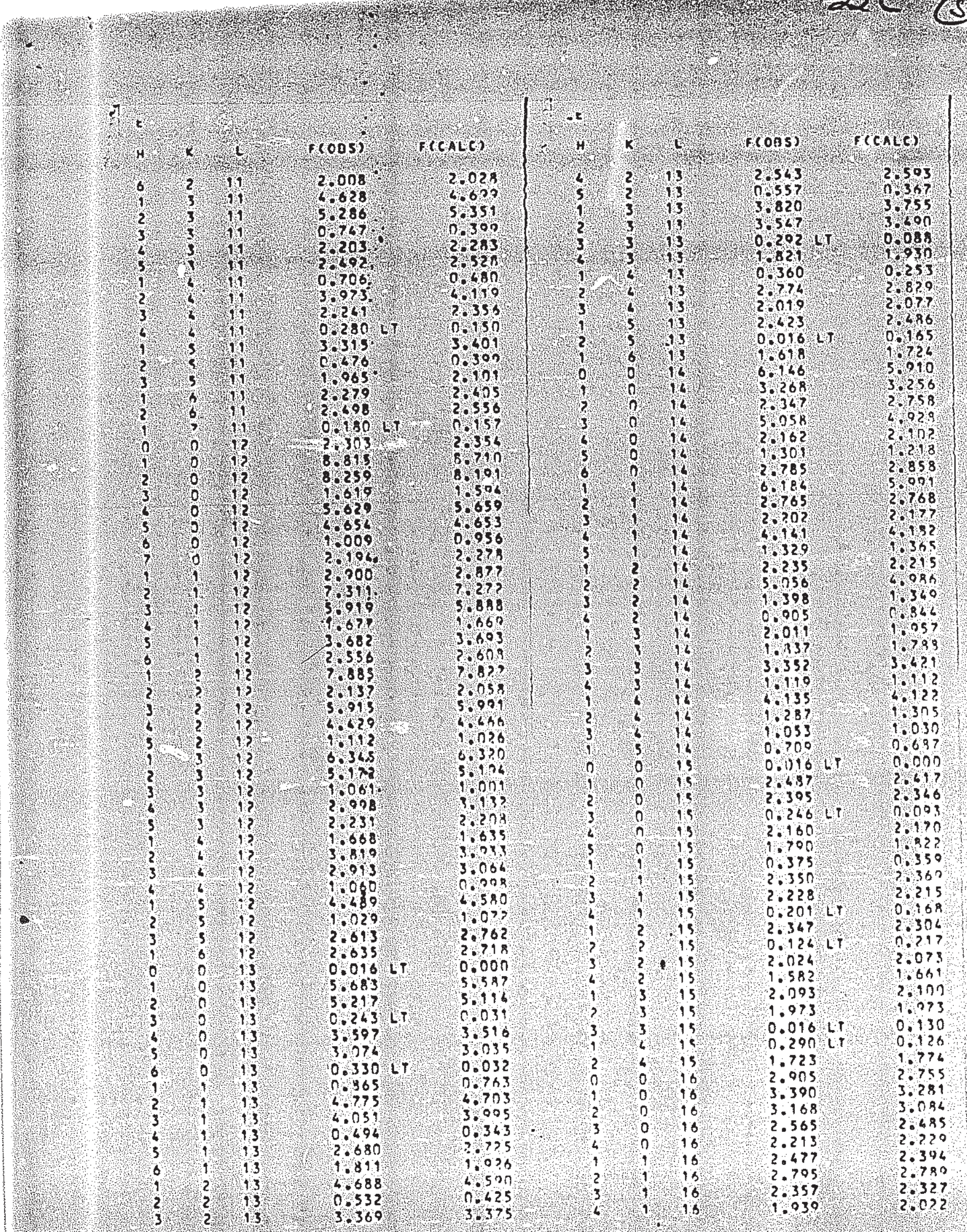




\section{$\because$}

$22 c$

te

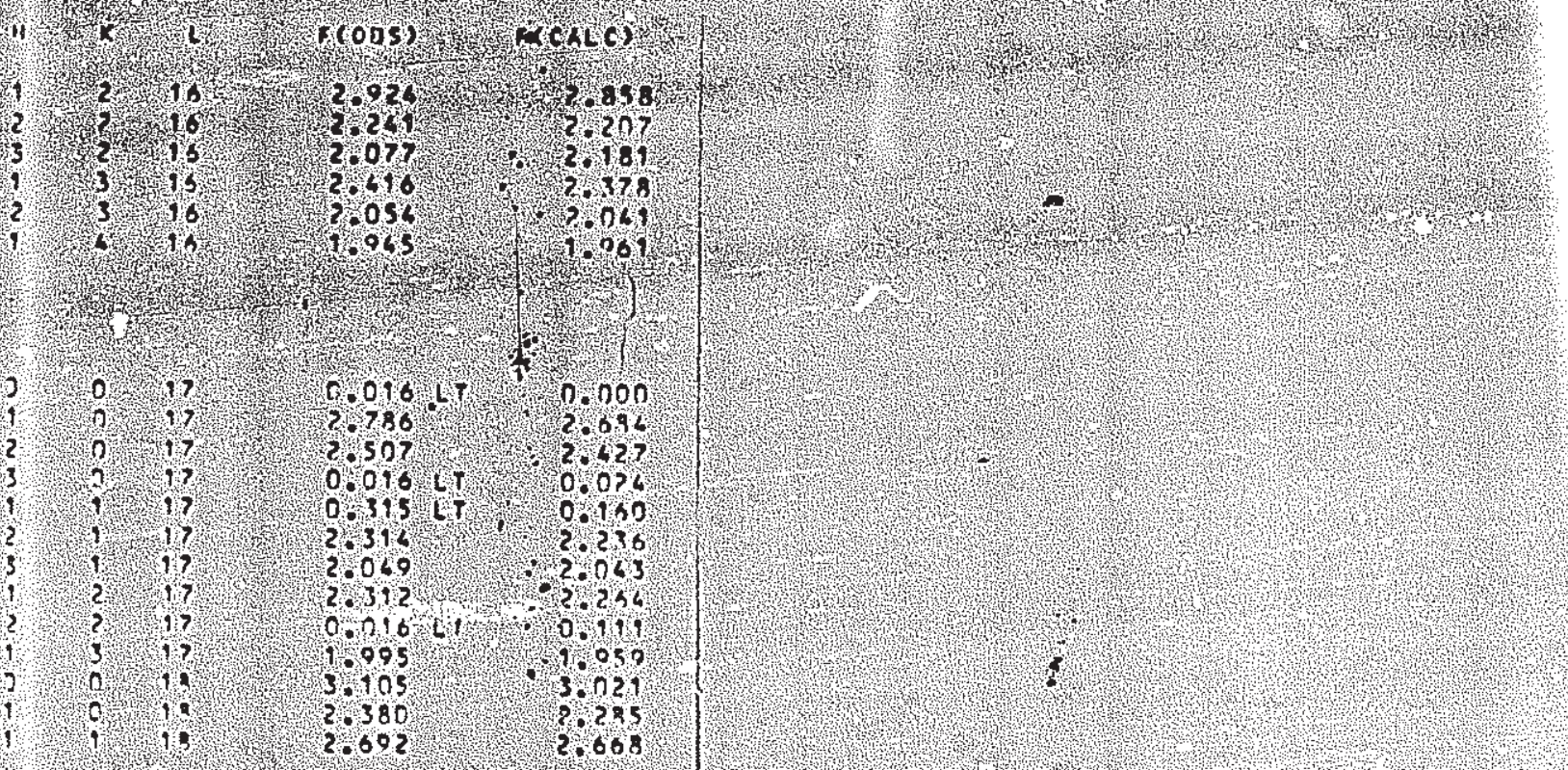




\section{[234]}

Hos 1 -

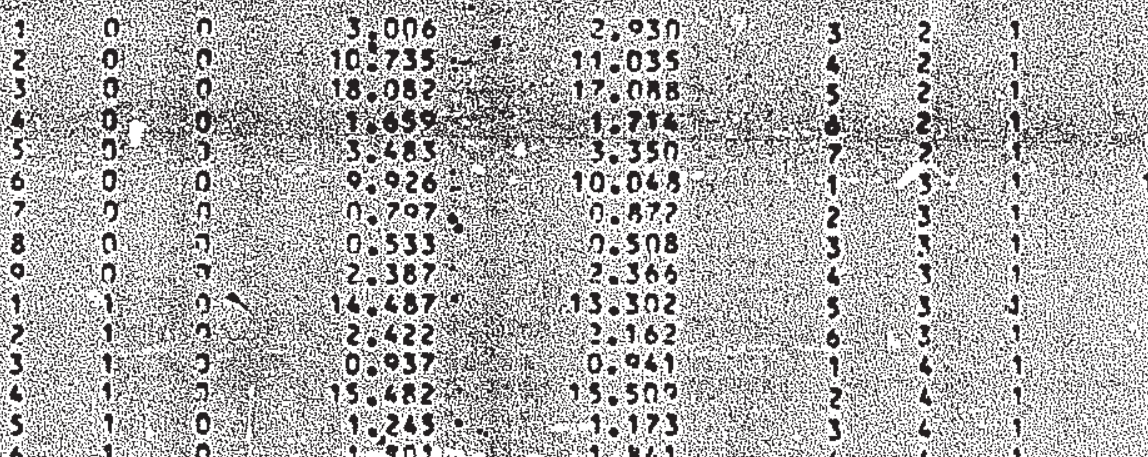
0.2 210 . 7 ,

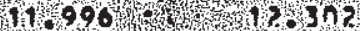

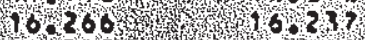

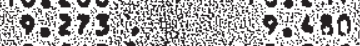

3262 2 3010

$10.6 \mathrm{~s}$.

1930.61038

16780.620

0.720 . 0.303

1360 ? 1750

140 . 1067

$0.260-2.71 \%$

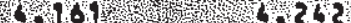

15.065 . 16.5\%

$0.45-6,0.190$

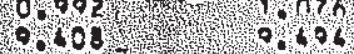

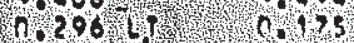

- 5181 13 3 ?

0.73 , 0.27

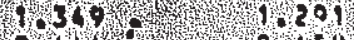

0.230740 .078

0.350 0.607

0.08602000

$7.126-7 \times 374$

$0.65 \%$. 0.37

0.379 . 0.678

$11.203 \quad 1031$ ?

10.567

4.460

10.926

13.288

1.397

$7.0 \%$

13.530

5.132

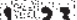

3.593

0049

5.231

10872

3.256

10.991

1.0 .54

0.616

8.456

2.629

0.672

2.707

4.534

10220

4046

12.079

6.509

0.068

1.612

$12 \% 53$

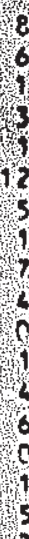

8. 227

6.185

3808

1. 5.8

2. 202

1. 553

7.306

6.12

.728

160

6.040

.373

177

2.1560

4158

2.216

2.607

2.13

$1,4 ? 2$

0.776

?. 360

1026

13.016

12.482

7.651

16.283

8.062

3.503

3. 47

1.10?

13.023

15.536

16336

4316

10.03

5.182

2.? 1

2.630

10.028

$8.9 ?$

6.71

8. 196

3.138

2.769

3.17

13.025

13.060

4,121

8.402

5.783

1.463

4.022

10.252

7.060

3.378

3.411

2.260
3.17?

6.00

$3.6 \%$

13263

5.37 ?

1.763

7. 316

4.157

1.340

4.064

6.083

12200

1.04 ?

2.001

4.61 ?

$\checkmark 070$

42

2,53

133

3,20 ?

2.020

$1051 \%$

$1 \% 313$

$7 \%, 78$

14. 132

0.119

8. 210

(.7.1?

1,505

0.058

12.95

14.751

h.365

0.066

2.213

2.36 ?

8. 184

6.414

.336

3.93 ?

2.676

3.024

14185
$2 \times 2$

4.197

3,42 ?

5.000

1.446

4.032

7102

3.475

3.43 


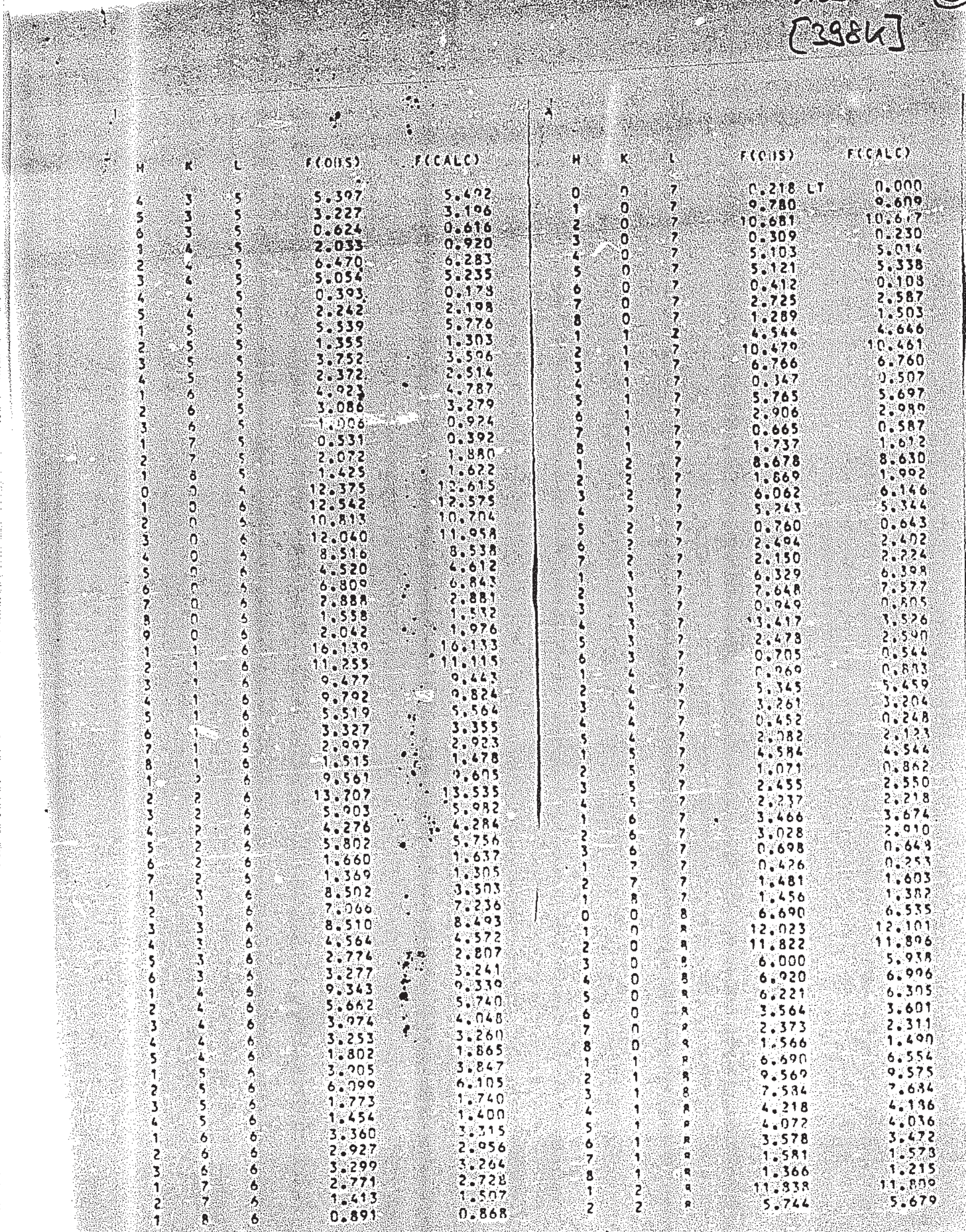




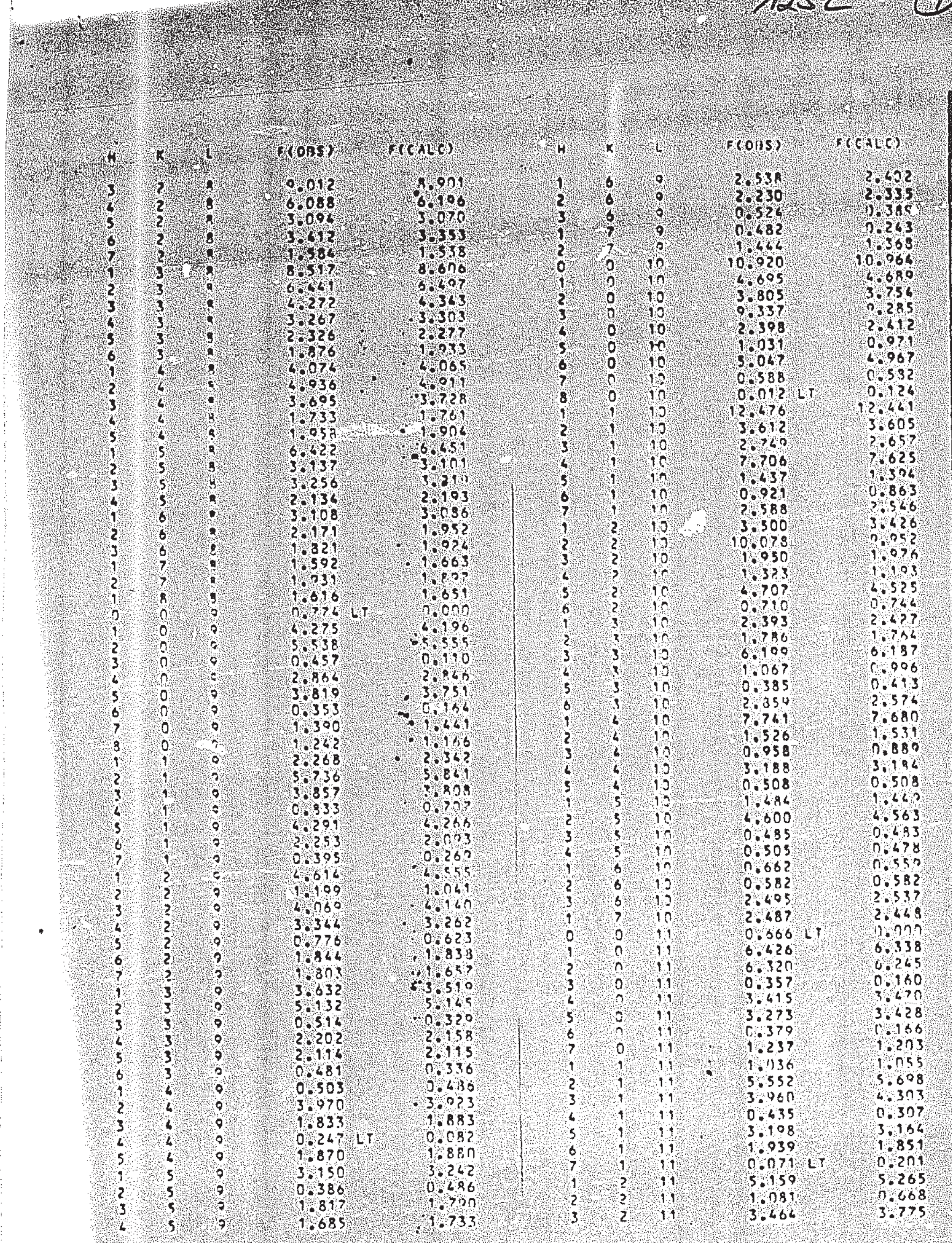




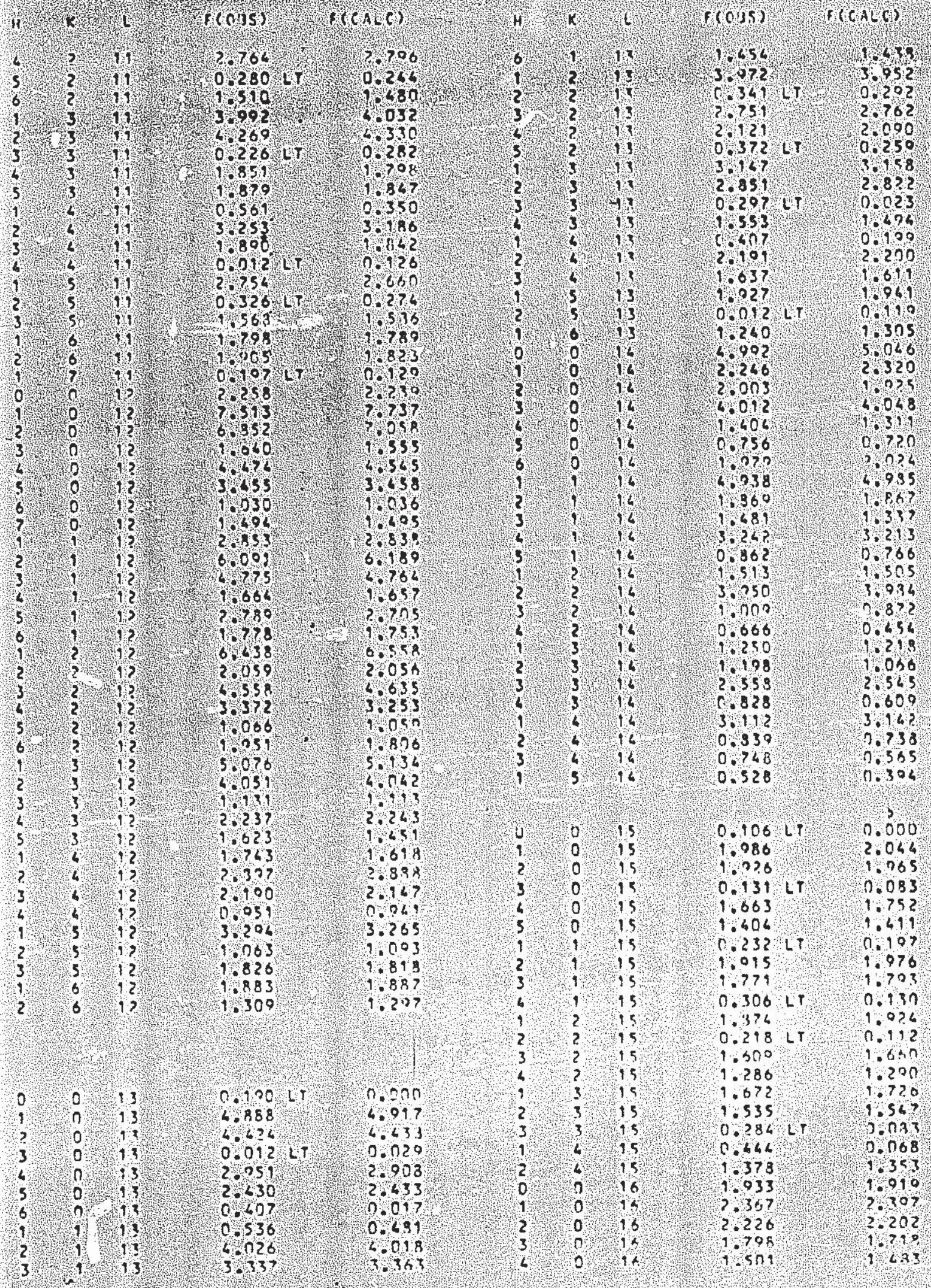


;. 


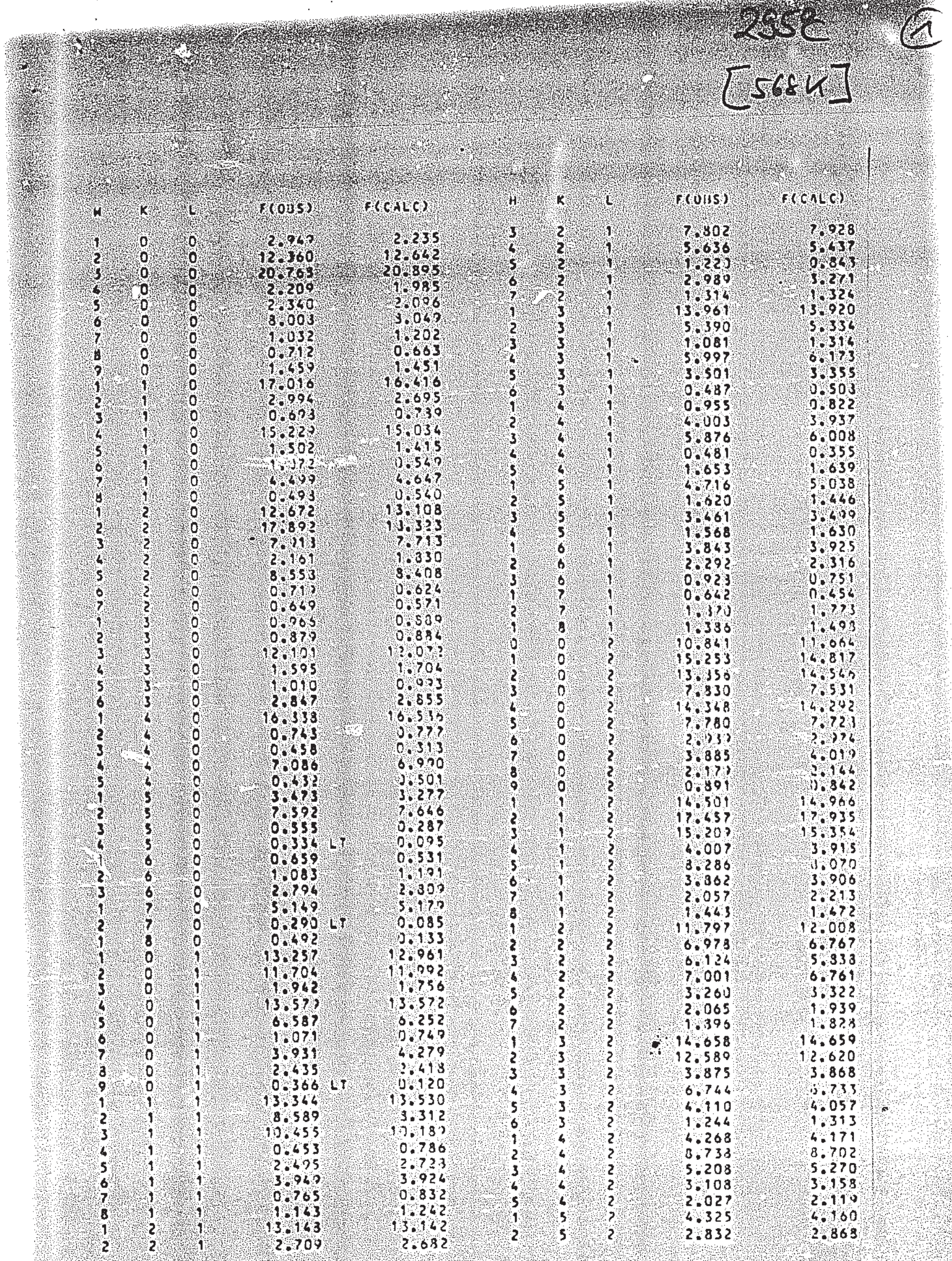




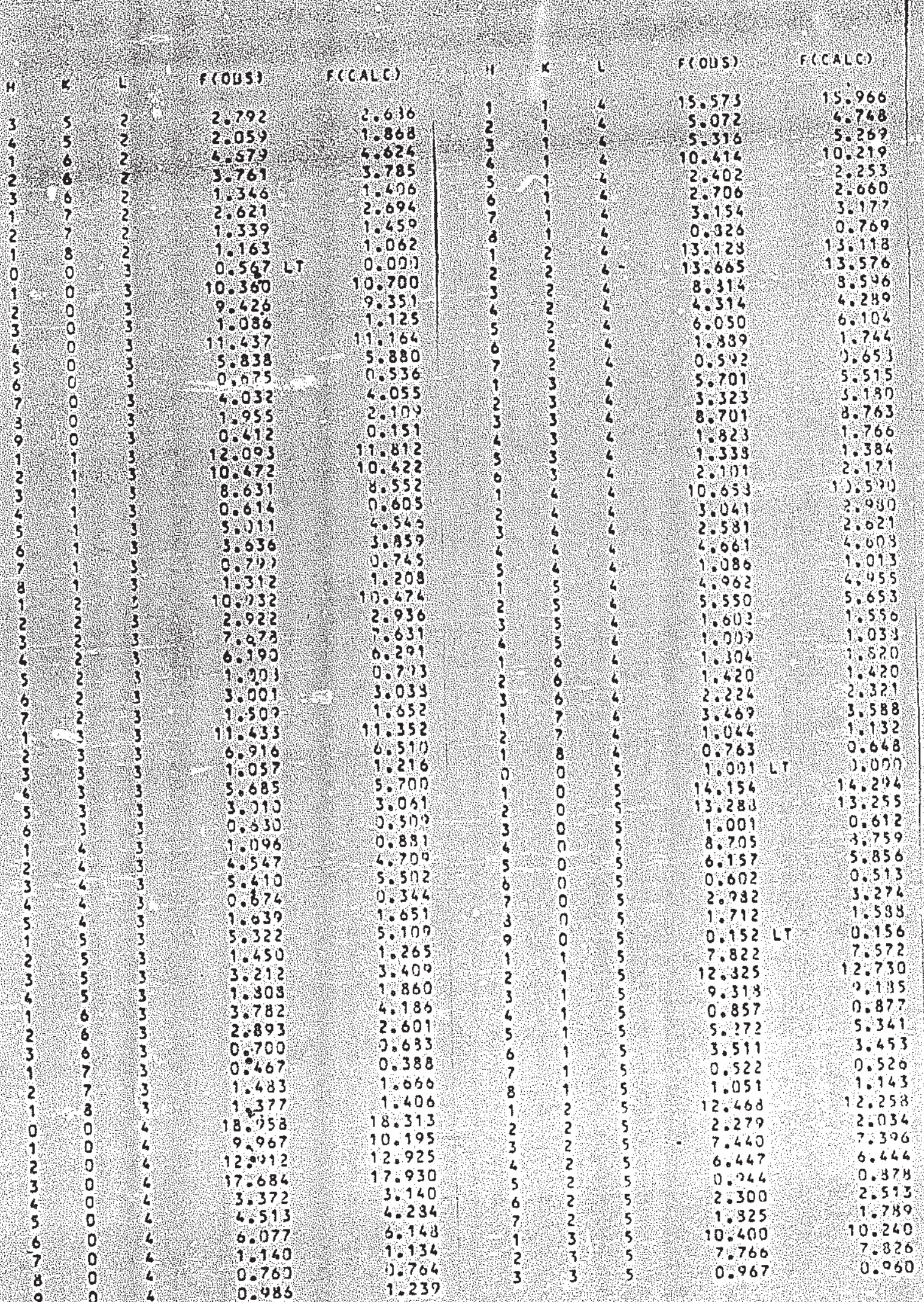




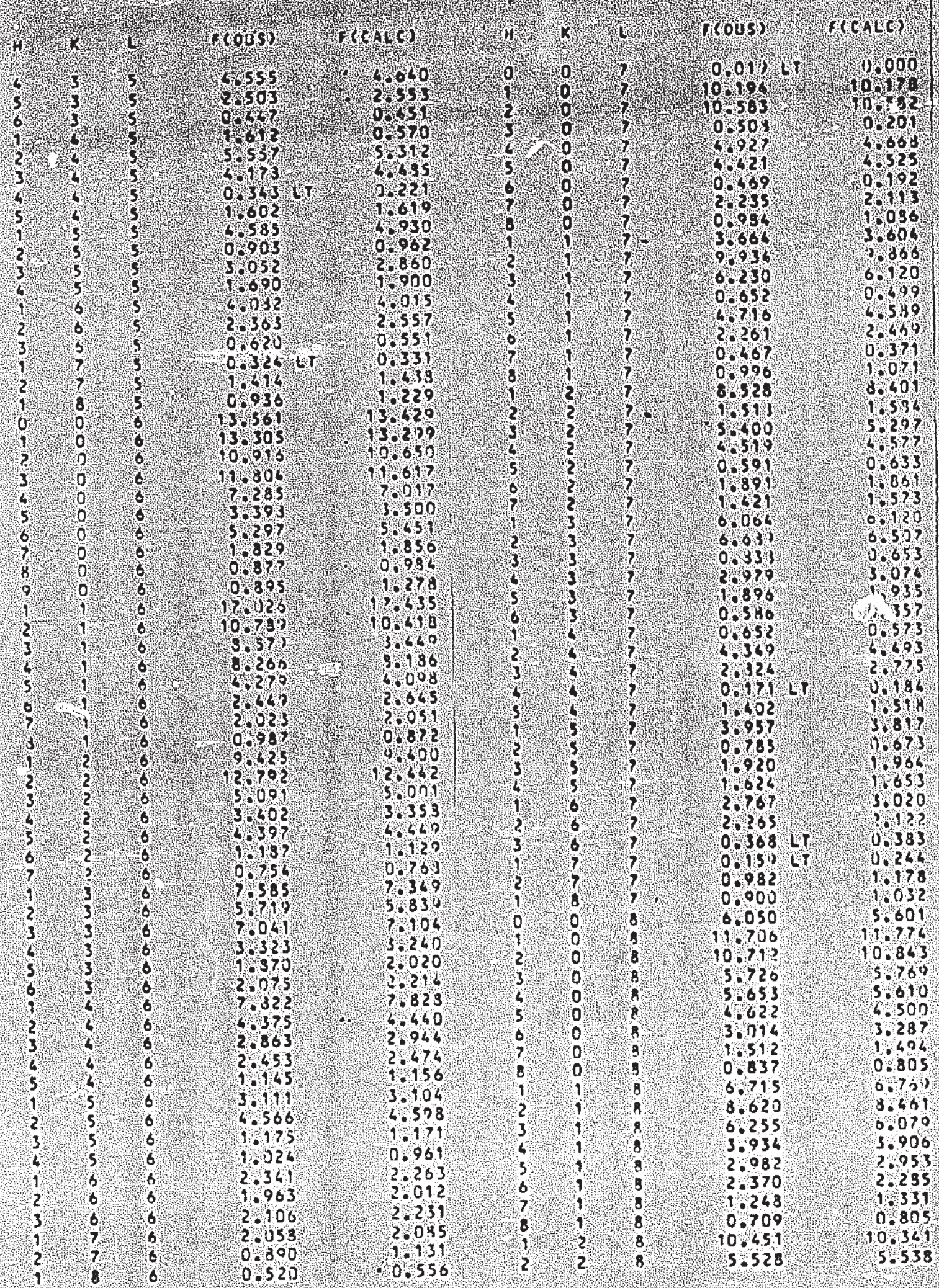




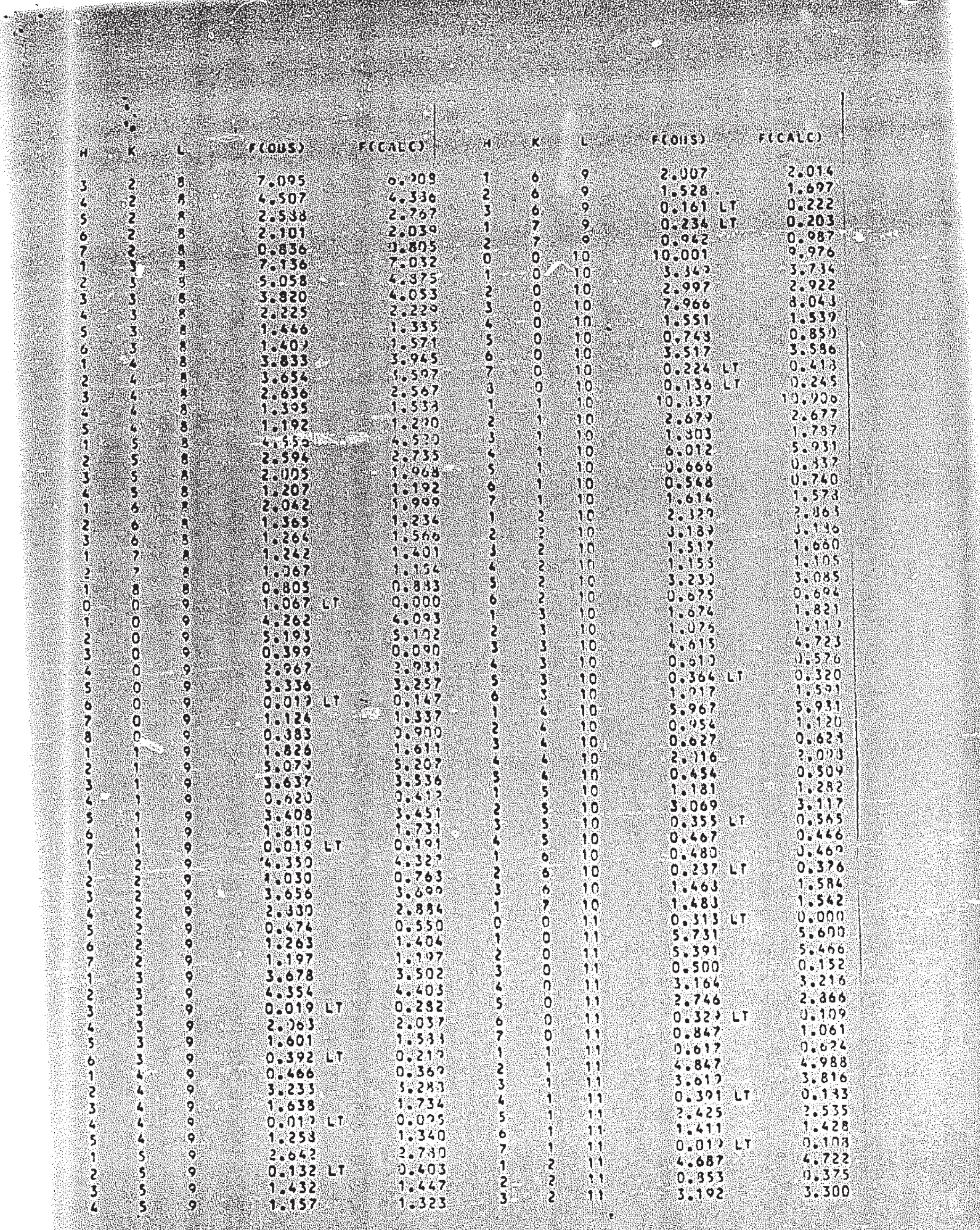









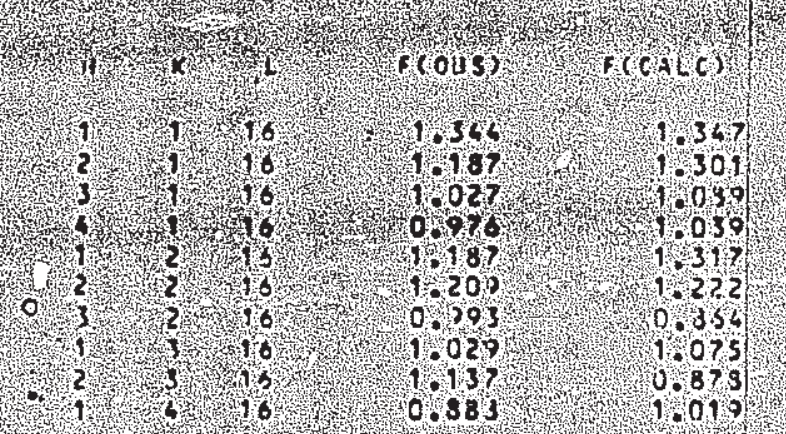

$\frac{1}{6}$

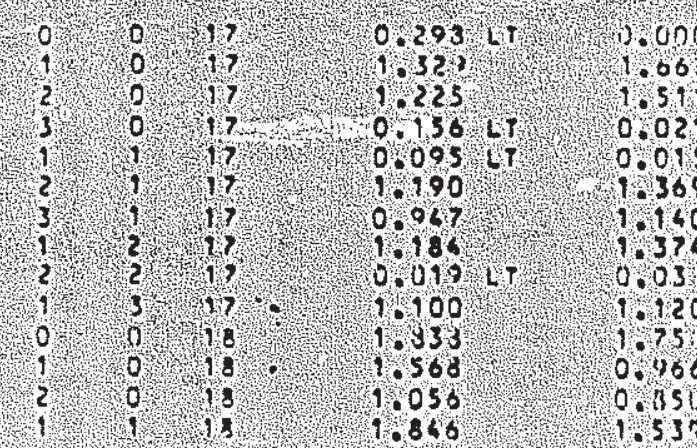

